\title{
METODE DAKWAH USTADZ SALAFIYAH DALAM MENGINTERNALISASIKAN NILAI- NILAI KEISLAMAN MELALUI PENGAJIAN RUTIN
}

\author{
Sukarta \\ Program Studi KPI, Universitas Muhammadiyah Mataram, Indonesia \\ nggihsilak@gmail.com
}

\section{INFO ARTIKEL}

\section{Riwayat Artikel:}

Diterima: 02-06-2021

Disetujui: 30-10 -2021

\section{Kata Kunci:}

Metode Dakwah, Ustadz- ustadz Salafiyah, Pondok Pesantren, Internalisasi Nilai- Nilai, Nilai- Nilai Keislaman

Keywords:

Da'wah method, Ustadz- ustadz Salafiyah, Boarding School, Internalization of Values, Islamic Values

\section{A. LATAR BELAKANG}

Islam adalah agama dakwah, yaitu agama yang menugaskan umatnya untuk menyebarkan dan menyiarkan Islam kepada seluruh umat manusia. secara umum tujuan dakwah Islam adalah mengjak umat manusia kepada jalan yang benar dan di ridhoi Allah subhanahu wata'alla, agar kita dapat hidup bahagiya di dunia dan akhirat. ${ }^{1}$

1 Asmuni Syukir, Dasar-Dasar Strategi Dakwah (Surabaya: A Ikhlas, 1983), hlm, 51.

\section{ABSTRAK}

Abstrak: Penelitian ini bertujuan untuk mengetahui Metode Dakwah Ustadz- ustadz Salafiyah Dalam Menginternalisasikan Nilai- Nilai Keislaman Melalui Pengajian Rutin Di Masjid Pondok Pesantren Abu Hurairah Mataram 2020. Pondok Pesantren Abu Hurairah mataram memiliki ustadz- ustadz (para ustadz) yang memberikan pengajian secara rutin di pondok pesantren Abu hurairah mataram untuk menginternalisasikan nilai- nilai keIslaman kepada jamaah di mataram. Dalam penelitian ini, peneliti menggunakan metode penelitian kualitatif deskriptif, dimana peneliti mendapatkan data dengan menggunakan kajian lapangan, sehingga peneliti juga dapat mengenali subjek dan merasakan apa yang terjadi, sehingga tujuan penelitian ini adalah mendapatkan gambaran rinci dari fenomena yang diteliti.Hasil dari penelitian ini menunjukkan bahwa. Terkait dengan respon jamaah terhadap dakwah ustadz- ustadz salafiyah pondok pesantren Abu hurairoh mataram beberapa tanggapan msyarakat yang merasakan dampak positif dengan adanya kajian rutin tersebut. Metode dakwah Ustadz- ustadz Salafiyah memiliki dua garis besar yaitu metode dakwah secara umum dalam bentuk pola seperti mengadakan halaqoh majelis ilmu, dauroh, mendirikan yayasan, mendirikan media siaran dakwah dan secara khusus dalam bentuk pelaksanaan pengajian rutin dengan pemateri dan materi yang sudah terjadwal rapi.

\begin{abstract}
: the researchers obtained data using field studies, so that researchers could also ognize the subject and feel what was happening, so that the purpose of this study was to get a icture of the phenomenon under study. The results of this study indicate that. Related to the response of the congregation to the preaching of the ustadz-ustadz salafiyah Islamic boarding school Abu Hurairoh Mataram, several community responses have felt a positive impact with the existence of this routine study. The method of preaching by Ustadz-ustadz Salafiyah has two broad outlines, namely the method of da'wah in general in the form of patterns such as holding halaqoh scientific assemblies, cycles, establishing foundations, establishing dakwah broadcast media and specifically in the form of carrying out routine recitation with presenters and well-scheduled materials.
\end{abstract}

Dakwah merupakan suatu keharusan dalam rangka mengemban agama Islam, aktivis dakwah yang maju akan membawa pengaruh terhadap agama dan sebaliknya, aktivitas dakwah yang lesu akan berakibat pada kemunduran agama. adanya hubungan timbal balik seperti itu, maka dapat di mengerti jika Islam meletakkan kewajianban dakawah pada setiap pemeluknya. ${ }^{2}$ kemajuan dan kemunduran umat Islam sangat berkaitan erat dengan kegiatan dakwah yang
${ }^{2}$ Andy Dermawan Dkk, Metologi Ilmu Dakwah (Yogyakarta: LESFI, 2002), hlm.13. 
dilakukanya. ${ }^{3}$ karena itu Al- Qur'an dalam menyebut kegiatan dakwah dengan Absanu Qaula ${ }^{4}$. dengan kata lain bisa disimpulkan bahwa dakwah menempati posisi yang tinggi dan mulia dalam dalam kemajuan agama Islam, tidak dapat dibayangkan apabila kegiatan dakwah mengalami kelumpuhan yang disebabkan oleh berbagai faktor terlebih pada era globalisasi sekarang ini, dimana berbagai informasi masuk begitu cepat dan instan yang tidak dapat dibendung lagi. Umat Islam harus dapat memilah dan menyaring informasi tersebut sehingga tidak bertentanggan dengan nilai- nilai Islam.

Dakwah Islam adalah tugas suci yang di bebankan kepada setiap muslim dimana saja ia berada sebagaimana termaktub dalam Al- Qur'an dan As- Sunnah Rasulullah Shalallahu'alaihi wassalam, kewajiban dakwah menyerukan dan menyampaikan agama Islam kepada masyarakat.

Dakwah Islam, dakwah yang bertujuan untuk memancing dan mengharapkan potensi diri manusia agar eksistensi mereka punya makna dihadapan Allah Subhanahu wata'ala. sekali lagi perlu ditegaskan disini bahwa tugas dakwah adalah tugas umat keseluruhan bukan hanya tugas kelompok tertentu umat Islam. ${ }^{5}$ oleh sebab itu dakwah bisa mencapai sasaran- sasaran strategis jangka panjang, maka tentunya di perlukan suatu sistem komunikasi yang baik dalam penataan perkataan maupun perbuatan yang dalam banyak hal sanagat relevan dan terkait dengan nilai- nilai ke Islaman, dengan adanaya kondisi seperti itu maka para dai harus mempunyai pemahaman yang mendalam dan tidak hanya sekedar menyampaikan saja melainkan harus memenuhi beberapa syarat, di antaranya mencari materi yang cocok, mengetahui psikologis objek dakwah secara tepat, memilih metode yang representative mengunakan bahasa yang bijaksana dan sebagainya. semua aspek di atas akan menjadi stressing point pembahasan dalam metode dakwah.

Usaha untuk menyebarkan dakwah Islam di tengah- tengah kehidupan umat manusia merupakan usaha dakwah yang harus dilaksanakan oleh umat Islam terutama dimasa yang akan datang akan bertambah berat dan kompleks, hal ini disebabkan masalah- masalah yang di semakin urgent sehingga dakwah dapat berkembang semakin kompleks. Dalam hal ini umat Islam perlu terus menerus mengali,

\footnotetext{
${ }^{3}$ Didin Hafidhudin, Dakwah Aktual (Jakarta: Gema Insani Press, 1998),hlm. 76.

${ }^{4}$ Al- Qur'an Surat Fushilat: 33.

5 Ahm. Syafi'I Ma'arif, Islam Dan Politik: Upaya Membingkai Peradaban, Jakarta: Pustaka Dinamik, 1999 h. 15
}

memaknai, dan mengaplikasikan dakwah sesuai dengan tuntunan dan perkembanagan kehidupan.

Ketika membahas tentang dakwah, kita harus merujuk pada Al-Qur'an dan as-sunah. seperti firman Allah di dalam Al-Qur'an surat AnNahl ayat 125:

"Serulah (manusia) kepada jalan tuhanmu dengan hikmah dan pelajaran yang baik dan bantahlah mereka dengan jalan yang baik. sesungguhnya tuhanmu dialah yang lebih mengetahui siapa yang tersesat dari jalanya dan dialah yang mengetahui orang- orang yang mendapat petunjuk."

Berdasarkan firman Allah dalam Al- Qur'an surat Al- Nahl ayat 125 menjelaskan bahwa dakwah Islam tidak mengharuskan secepatnya berhasil dengan satu cara atau metode saja, namun berbagai cara dapat dilakukan sesuai objek dakwah dan kemampuan masing- masing pelaksana dakwah. Pondok pesantren abu hurairah mataram memiliki ustadz- ustadz (para ustadz) yang memberikan pengajian secara rutin di masjid teladan imam syafii lading- lading kabupaten tanjung lombok utara sebelum covid-19 namun setelah covid-19 maka kajian keislaman dipindahkan ke masjid pondok pesantren abu hurairah mataram untuk menginternalisasikan nilai- nilai keislaman kepada masyarakat di ladinglading dan ataram. daerah lading- lading termasuk daerah yang lokasinya perdesaan dan cukup jauh dari pusat pendidikan seperti pondok pesantren, setelah ustadz- ustadz pondok pesantren abu hurairah mengadakan dakwah rutin di ladinglading maka sambutan masyarakat sangat antusias sehingga saat ini sudah di bentuk yayasan teladan imam syafi'i dan di atas lahan milik yayasan teladan imam syafi'i inilah di bangun sebuah majid yang menjadi pusat dakwah ustadz- ustadz pondok pesantren abu hurairah. adapun di mataram ustadz- ustadz salafiyah memiliki markaz besar di pondok pesantren abu hurairah mataram, maka peneliti tertarik untuk meneliti metode dakwah ustadz- ustadz salafiyah dalam menginternalisasikan nilai- nilai keislaman melalui pengajian rutin di lading- lading lombok utara dan masjid pondok pesantren abu hurairah mataram.

\section{A. METODE PENELITIAN}

Jenis penelitian yang digunakan peneliti adalah penelitian kualitatif, penelitian kualitatif adalah penelitian yang menghasilkan penemuanpenemuan yang tidak dapat dicapai dengan menggunakan prosedur statistik atau dengan caracara kuantifikasi. Penelitian kualitatif dapat 
menunjukan kehidupan masyarakat, sejarah, tingkah laku, dan hubungan kekerabatan. ${ }^{6}$

Dalam Penelitian ini peneliti menggunakan pendekatan psikologis dalam studi islam, psikologi merupakan disiplin ilmu yang mendalami masalahmasalah yang berhubungan dengan kejiwaan seseorang yang tergambar dalam prilaku manusia. Objek dari psikologi adalah jiwa manusia yang bersifat abstrak dan tidak kongkrit. Ilmu psikologi ini dapat di gunakan sebagai acuan untuk meneliti dan menganalisa keberagaman yang terjadi dimasyarakat termasuk pada masyarakat muslimin, hal yang di kaji dalam studi islam adalah dengan mengunakan pendekatan psikologi antara agam dan jiwa manusia serta gejala manusia dengan tingkah laku di dalam hubugan agama islam. Psikologi agama, psikologi merupakan kata dari bahasa yunani "psyche"yang berarti jiwa dan" logos"berate ilmu pengetahuan jadi dapat di simpulkan bahwa psikologi adalah ilmu jiwa baik itu tentang gejala atau proses yang banyak mempengaruhi kejiwaan manusia terutama agam. Mayoritas manusia sudah tentu menganut agama tertentu sebagai kebutuhan rohani pengaruh agama terhadap kejiwaan manusia inilah yang mendorong lahirnya psikologi agama. Psikologi agama merupakan kajian ilmu tentang kehidupan beragama serta menganalisa pengaruh agama dalam menentukan sikap dan tingkah laku manusia dalam di siplin ilmu untuk mempelajari kejiwaan manusia dan latar belakang pengaruh keyaknan terhadap agama. Atau dengan kata lain psikologi agama hanya mengkaji sikap batin seseorang serta penghayatan batinya yang menimbulkan perasaan tenang, damai, tentram, pasrah dan sikap lainya yang ditunjukan melalui tinkah laku manusia yang perlu ditekan kan disini pendekatan psikologis adalah pendekatan yang hanya sebatas menelaah jiwa manusia. Maka objek utamanya hanya jiwa manusia yang berkaitan dengan agama.

Penggunaan pendekatan sosiologi lebih tepat untuk digunakan dalam penelitian ini, karena penulis ingin mengetahui lebih dalam dan detail tentang metode dakwah ustadz- ustadz salafiyahPondok Pesantren Abu Hurairah.

\section{B. HASIL DAN PEMBAHASAN}

Dakwah Salafiyah di pulau Lombok menurut beberapa sumber dimulai dari Kabupaten Lombok Timur sekitar tahun 1990. Dakwah Salafiyah dibawa oleh TGH. Husni Jamaluddin, putra seorang tuan guru NU kelahiran Bagek Nyaka, desa Kembang Kerang, kecamatan Aikmel.

${ }^{6}$ M. Junaidi Ghony dan Fauzan Almanshur, Metode Penelitian Kualitatif, Ar-Ruzz Media, Jogjakarta, 2016, hlm.25.
Besarnya pengaruh ayahnya menyebabkan TGH. Husni dalam waktu yang tidak relatif lama mendapatkan pengikut cukup banyak. Tak heran tahun 1995,pengikutnya hampir tersebar di semua desa di Lombok Timur. ${ }^{7}$

Dakwah Salafiyah juga berkembang dan menyebar di tengah masyarakat dengan intensitas yang cukup tinggi dengan munculnya beberapa lembaga pendidikan dan pengajian yang berbasis Dakwah Salafiyah. Di Lombok Barat dan di Lombok Timur terdapat beberapa pondok pesantren dan beberapa masjid yang dijadikan sebagai basis Dakwah Salafiyah. ${ }^{8}$ Pola dakwah salafiyah lebih kepada menyampaikan ajaran Islam lewat kajiankajian yang dilakukan di masjid.

Dari hasil observasi peneliti menemukan Metode dakwah Asatdizah Salafiyah memiliki dua garis besar yaitu metode dakwah secara umum dalam bentuk pola dan secara khusus dalam bentuk pelaksanaan pola metode dakwah tersebut ${ }^{9}$

Peneliti sebelumnya ditugaskan di Ladinglading Lombok Utara dan melaksanakan penelitian sekitar satu bulan di daerah Lading-lading Lombok Utara dan selanjutnya terjadi Covid-19 yang menyebabkan kegiatan dakwah ustadz- ustadz salafiyah pondok pesantren Abu Hurairah Mataram berpindah lokasi ke Masjid Pondok Pesantren Abu hurairah Mataram sehinggan selanjutnya peneliti melaksanakan penelitian di Obyek Pusat pelaksanaan dakwah asatdizah salafiyah setelah Covid-19.

\section{A. Metode Dakwah Secara Umum dalam bentuk Pola Metode Dakwah Ustadz- ustadz Salafiyah Pondok Pesantren Abu Hurairoh}

\section{Metode Dakwah dengan Pola Halaqah Majelis Ilmu dan Daurah}

Di kalangan Ustadz- ustadz Salafiyah tidak mengenal bahkan tidak diperbolehkan mendirikan sebuah partai politik. Dalam menyebarkan ajaranajarannya, mereka menggunakan sebuah metode dakwah yang dikenal dengan daurah dan halaqah atau majelis ilmu. Daurah secara bahasa berarti "giliran". Sedangkan menurut istilah yaitu suatu pelatihan atau pengajian yang diadakan dalam waktu dan tempat tertentu yang telah disepakati, disaat itu peserta berkumpul untuk mengikuti kegiatan yang telah direncanakan. Halaqah menurut bahasa bermakna "lingkaran". Sedangkan

${ }^{7}$ Yusuf Tantowi, Mengurai Konflik Sunnah VS Bid'ah di Pulau Seribu Masjid, Kumpulan Tulisan dalam Agama dan Pergeseran Representasi, Konflik dan Integrasi di Indonesia, (Jakarta: The Wahid Institute, 2009), hal. 27.

${ }^{8}$ Faizah, Gerakan Salafi Di Lombok, Jurnal Multikultural dan Multi Religius, 2012, Vol. 11, hal. 56-57.

${ }^{9}$ Hasil Observasi bulan Maret 2020. 
menurut istilah yaitu forum untuk mempelajari ilmu-ilmu keislaman, dimana seorang ustaz atau pengajar memberikan pelajaran-pelajaran berdasarkan buku-buku tertentu dan para peserta atau murid-muridnya duduk melingkar untuk mendengarkan dan menyimak materinya. Tempat yang biasa dipakai untuk kegiatan daurah dan halaqah biasanya masjid, ruang pertemuan, dan rumah sang ustaz. Tidak sedikit dari kegiatan ini melahirkan sebuah lembaga pendidikan, pondok pesantren dan kursus bahasa Arab.

\section{Metode Dakwah dengan pola mendirikan yayasan}

Meningkatnya generasi muda yang mengikuti kegiatan- kegiatan yang bermanhaj Salafi hasil dari daurah dan halaqah membuktikan bahwa dakwah model tersebut berhasil. Para tokoh Salafi kemudian berfikir agar mereka tidak lagi mengikuti ajaran dan pemahaman yang keluar dari koridor salaf al-shalih. Menyikapi hal tersebut, para tokoh Salafi mendirikan yayasan yang kemudian berkembang menjadi lembaga pendidikan seperti pondok pesantren dan lembaga kursus bahasa Arab. Hal ini dimaksudkan agar kegiatan halaqah dan daurah bisa diselenggarakan lebih efektif dan efesien. Setidaknya ada tiga lembaga yang membiayai keberlangsungan yayasan-yayasan tersebut, yaitu:

1. Jam'iyyat Ihya al-Turats al-Islami atau dikenal Ihya Turats berpusat di Kuwait. Lembaga ini diawasi oleh pemerintah Kuwait dan otoritas keagamaan Arab Saudi.

2. Mu'assasat al-Haramain adalah lembaga yang bekerja sama dengan Kementerian Masalahmasalah Islam, Sumbangan, Dakwah, dan Bimbingan. Berdiri tahun 1980 yang bertujuan menerapkan ajaran Islam yang benar dan mendidik para generasi. Lembaga ini juga memberikan bantuan dana untuk pendirian masjid dan kegiatan dakwah lainnya.

3. Organisasi Amal Islam Internasional yang berkedudukan di Dammam, Arab Saudi. Lembaga ini fokus dalam memberikan dana sosial dan keagamaan. ${ }^{10}$

Adapun yayasan yang dibangun di Lombok cukup banyak, diantaranya :

- Yayasan Al Hunafa, bertempat di Gomong, Mataram. Yayasan ini menaungi Pondok Pesantren Abu Hurairah Mataram

- Yayasan Al Fauzan, Muhandisul Khoir, Lu'lu AlGaanim yang bertempat di Lombok Timur

${ }^{10}$ Muhamad Ali Chozin, jurnal tentang strategi dakwah Salafi di Indonesia, hal.16-17
- Yayasan Teladan Imam Syafi'i yang bertempat di Lombok Utara ${ }^{11}$

Metode Dakwah dengan pola Mendirikan dan Mengembangkan Media Siaran

Pentingnya sebuah komunikasi membuat kalangan Salafi membuat dan mengembangkan media komunikasi, misalnya: stasiun televisi dan radio, website, dan penerbit. Di bawah ini, penulis akan menyebutkan beberapa media komunikasi yang didirikan oleh kalangan Salafi di Lombok.

a. Stasiun televisi, antara lain: Rinjani TV, Lombok Bertauhid.

b. Stasiun radio, antara lain: Radio Suara Qur'an 106,7 fm di Lombok Timur.

Metode Dakwah Ustadz- ustadz Salafiyah Pondok Pesantren Abu Hurairah Dalam Menginternalisaikan Nilai- Nilai Keislaman Melalui Pengajian Rutin

Dalam Al-Qur'an disebutkan ada beberapa metode dakwah yang perlu tempuh oleh seorang da'i, pada surat An-Nahl ayat 125 Allah Ta'ala;

"Serulah manusia kepada jalan Tuhanmu dengan hikmah dan pelajaran yang baik dan bantahlah mereka dengan cara yang baik. Sesungguhnya Tuhanmu Dialah yang lebih mengetahui tentang siapa yang tersesat di jalan-Nya dan Dialah yang lebih mengetahui orang-orang yang mendapat petunjuk.

Dari ayat diatas tersebut dapat diambil pemahaman bahwa bentuk-bentuk dakwah itu meliputi tiga cara;

Al-Hikmah, Ibnu Qoyim berpendapat bahwa pengertian hikmah yang paling tepat adalah seperti yang dikatakan oleh Mujahid dan Malik yang mendefisinikan bahwa hikmah adalah pengetahuan tentang kebenaran dan pengalamannya, ketepatan sperkataan dan pengalamannya. Hal ini tidak bisa dicapai kecuali dengan memhami Al-Qur'an, mendalami syari'atsyari'at Islam serta hakikat iman. ${ }^{12}$

Al-Hikmah menurut Toha Yahya Umar (Munzier dan Harjani) mengatakan bahwa hikmah berarti meletakan sesuatu pada tempatnya dengan berpikir, berusaha menyusun dan mengatur dengan cara yang sesuai keadaan zaman dengan tidak bertentangan dengan larangan Tuhan (Alloh subhanahu wa ta'ala).13

Menurut syaikh Zamakhsari dalam kitabnya"alkasyaf" al-hikmah adalah perkataan yang pasti

\footnotetext{
${ }^{11}$ Kutipan ceramah Ustaz Ahmad Zawawi Nawawi, Lc. "kisah perjuangan pesatnya Dakwah Sunnah di Lombok" tahun 2019

${ }_{12}$ H.Munzier dan H.Harjani, Metode Dakwah, cet 4, Prenadamedia Group, Jakarta, 2015, hlm.10.

${ }^{13}$ Ibid. hlm.8.
} 
benar. Ia adalah dalil yang menjelaskan kebenaran dan menghilangkan keraguan atau kesamaran. Selanjutnya syaikh Zamakhsari mengatakan hikmah juga diartikan sebagai Al-Qur'an yakni ajaklah mereaka (manusia) mengikuti kitab yang memuat hikmah.

Al-Mau'idza Al-hasanah, Secara bahasa, mau'izhahhasanah terdiri dari dua kata, yaitu mau'izhah dan hasanah. Kata mau'izhah berasal dari kata wa'adza-ya'idzu-wa'dzan-'idzatan yang berarti nasihat, bimbingan, pendidikan dan peringatan, sementara hasanah merupakan kebalikan dari sayyi'ah yang artinya kebaikan lawannya kejelekan.14

Al-Mujadalah Bi-al-Lati Hiya Ahsan, Dari segi etimologi lafazh mujadalah diambil dari kata"jadala" yang bermakna memintal, melilit. Kata "jadala" dapat bermakna menarik tali dan mengikatnya guna menguatkan sesuatu. Orang yang berdebat bagaikan menarik dengan ucapan untuk mneyakinkan lawannya dengan menguatkan pendapatnya melalui argumentasi yang disampaikan.

Sedangkan pengertian mujadalah menurut (terminologi) istilah adalah upaya tukar pendapat yang dilakukan oleh dua belah pihak secara sinergi tanpa adanya suasana yang mengharuskan lahirnya permusuhan diantara keduanya. ${ }^{15}$

Dibawah ini akan dipaparkan hasil wawancara peneliti dengan responden yang merupakan ustadz- ustadz salafiyah

Pertanyaan : metode dakwah apa yang Ustadz terapkan dalam menyampaikan kajian-kajian terhadap jamaah?

Jawaban : Antum pernah tidak menonton kajian ana di youtube? Jika antum pernah menonton kajian ana di youtube maka antum akan bisa menilai sendiri metode apa yang saya terapkan dalam menyampaikan dakwah".16

Setelah peneliti melakukan wawancara dengan mudir sekaligus ustadz salafiyah di atas maka dapat diambil kesimpulan salah satu metode dakwah yang digunakan adalah dengan menggunakan media sosial seperti you tube.

Dalam pelaksanaan pengajian di masjid pondok pesantren Abu hurairah ustadz sangat berantusias dalam menyampaikan dakwah terindikasi dengan intonasi suara yang tegas dan

\footnotetext{
${ }^{14}$ Ibid. hlm.10

H.Munzier dan H.Harjani, Metode Dakwah, cet 4 Prenadamedia Group, Jakarta, 2015, . hlm 18.

${ }^{16}$ Fakhrudin Abdurrahman, Lc. M.Pd.I, Pimpinan (mudir pondok pesantren Abu hurairah mataram),, wawancara pada senin, 06 juli 2020 bakda isya.
}

lugas, sedangkan jamaah yang hadir cukup banyak sekitar 80 orang dengan menggunakan protokol covid-19 yang telah ditetapkan seperti menggunakan masker, mengatur jarak. ${ }^{17}$

Proses pengajian berlangsung tenang dan aman serta menggunakan media LCD, pengaturan jarak jamaah karena covid-19.18

Pertanyaan yang sama tentang metode dakwah juga peneliti ajukan kepada usatdz salafiyah lainnya yaitu usatdz Mashuri, Lc. Sebagaimana wawancara dibawah ini

Pertanyaan : metode dakwah apa yang Ustadz terapkan dalam menyampaikan kajian-kajian terhadap jamaah?

Jawaban: metode yang ustad gunakan ceramah dan membaca kitab yang berjudul qowaidul arba' dan mengartikanya serta menjelaskan apa yang dimaksud isi didalam kitab tersebut, menyuruh jamaah untuk membacakan hadis dan ustad membenarkan ketika salah mengajarkan para jamaah membaca ayat dan hadis yang benar. ${ }^{19}$

Setelah peneliti melakukan wawancara dengan ustadz mashuri badran di atas maka dapat diambil kesimpulan salah satu metode dakwah yang digunakan adalah dengan menggunakan ceramah, membaca,mengartikan dan menjelaskan isi kitab qowaidul arba'.

Dalam pelaksanaan pengajian di masjid pondok pesantren Abu hurairah ustadz membahas kitab ma'alim manhaj ahlis sunnah wal jama'ah metode penyampaianya mengunakan kitp yang dibaca dan diartikan serta menjelaaskanya kepada jaam, sedangkan jamaah yang hadir sekitar 60 orang dengan menggunakan protokol covid-19 yang telah ditetapkan seperti menggunakan masker, mengatur jarak selain itu ada doprais yang diberikan setelah selesai pengajian yang bisa menjawab pertanyaan dari ustadz maka akan mendapatkan doprais berupa jubah dan masker

Proses pengajian berlangsung tenang dan aman serta menggunakan media LCD, pengaturan jarak jamaah karena covid-19.

Ustadz yang lain juga menguatkan hal tersebut sebagaimana hasil wawancara dengan Ustadz ahmad firdaus, Lc berikut ini :

Pertanyaan : metode dakwah apa yang Ustadz terapkan dalam menyampaikan kajian-kajian terhadap jamaah?

Jawaban: metode yang ustad gunakan ceramah dan membaca kitab yang berjudul ma'alim manhaj ahlis

\footnotetext{
17 Hasil Observasi di Masjid Pondok Pesantren Abu Hurairah Mataram pada senin, 06 juli 2020. Waktu pengajian bakda magrib dan Isya.

${ }^{18}$ Dokumentasi berupa photo proses pengajian pada senin, 06 juli 2020. Waktu pengajian bakda magrib - Isya terdapat di lampiran.

${ }^{19}$ Wawancara dengan Ustadz Mashuri badran, Lc. (ustadz pondok pesantren Abu hurairah mataram),, wawancara pada minngu, 12 juli 2020 bakda isya.
} 
sunnah wal jama'ah dan mengartikanya serta menjelaskan apa yang dimaksud isi didalam kitab tersebut, menyuruh jamaah untuk membacakan hadis dan ustad membenarkan ketika salah mengajarkan para jamaah membaca ayat dan hadis yang benar. ${ }^{20}$

Setelah peneliti melakukan wawancara dengan ustadz Ahmad Firdaus di atas maka dapat diambil kesimpulan salah satu metode dakwah yang digunakan adalah dengan menggunakan ceramah, membaca,mengartikan dan menjelaskan isi kitab ma'alim manhaj ahlis sunnah wal jama'ah.

Dalam pelaksanaan pengajian di masjid pondok pesantren Abu hurairah ustadz membahas kitab ma'alim manhaj ahlis sunnah wal jama'ah metode penyampaianya mengunakan kitab yang dibaca dan diartikan serta menjelaaskanya kepada jaam, sedangkan jamaah yang hadir sekitar 70 orang dengan menggunakan protokol covid-19 yang telah ditetapkan seperti menggunakan masker, mengatur jarak selain itu ada doprais yang diberikan setelah selesai pengajian yang bisa menjawab pertanyaan dari ustadz maka akan mendapatkan doprais berupa jubah dan masker

Proses pengajian berlangsung tenang dan aman serta menggunakan media LCD, pengaturan jarak jamaah karena covid-19.

Metode Ustadz lainnya juga hampir sama dengan dibuktikan oleh hasil wawancara dengan Ustadz Jamaluddin berikut ini :

Pertanyaan : metode dakwah apa yang Ustadz terapkan dalam menyampaikan kajian-kajian terhadap jamaah?

Jawaban: metode yang ustad gunakan ceramah dan membaca kitab yang berjudul aqidah dan manhaj, sserta mengartikanya serta menjelaskan apa yang dimaksud isi didalam kitab tersebut, menyuruh jamaah untuk membacakan hadis dan ustad membenarkan ketika salah mengajarkan para jamaah membaca ayat dan hadis yang benar. ${ }^{21}$

Setelah peneliti melakukan wawancara dengan ustadz mashuri badran di atas maka dapat diambil kesimpulan salah satu metode dakwah yang digunakan adalah dengan menggunakan ceramah, membaca,mengartikan dan menjelaskan isi kitab aqidah dan manhaj.

Dalam pelaksanaan pengajian di masjid pondok pesantren Abu hurairah ustadz membahas kitab ma'alim manhaj ahlis sunnah wal jama'ah metode penyampaianya mengunakan kitp yang dibaca dan

\footnotetext{
20 Wawancara dengan Ustadz Ahmad firdaus, Lc. (ustadz pondok pesantren Abu hurairah mataram), wawancara pada senin, rabu 15 juli 2020 bakda isya.

21 Wawancara dengan Ustadz Jamaluddin, Lc. (ustadz pondok pesantren Abu hurairah mataram), wawancara pada kamis 16 juli 2020 bakda isya.
}

diartikan serta menjelaaskanya kepada jaam, sedangkan jamaah yang hadir sekitar 55 orang dengan menggunakan protokol covid-19 yang telah ditetapkan seperti menggunakan masker, mengatur jarak selain itu ada doprais yang diberikan setelah selesai pengajian yang bisa menjawab pertanyaan dari ustadz maka akan mendapatkan doprais berupa jubah dan masker ${ }^{22}$

Proses pengajian berlangsung tenang dan aman serta menggunakan media LCD, pengaturan jarak jamaah karena covid-19.

Ustadz yang lain juga mengutakan dengan metode dakwah yang sama yaitu ceramah dengan membahas kitab seperti wawancara dengan Ustad mufi tahlib berikut ini:

Pertanyaan : metode dakwah apa yang Ustadz terapkan dalam menyampaikan kajian-kajian terhadap jamaah?

Jawaban: metode yang ustad gunakan ceramah dan membaca kitab yang berjudul adab, serta mengartikanya serta menjelaskan apa yang dimaksud isi didalam kitab tersebut, menyuruh jamaah untuk membacakan hadis dan ustad membenarkan ketika salah mengajarkan para jamaah membaca ayat dan hadis yang benar. ${ }^{23}$

Setelah peneliti melakukan wawancara dengan ustadz mashuri badran di atas maka dapat diambil kesimpulan salah satu metode dakwah yang digunakan adalah dengan menggunakan ceramah, membaca,mengartikan dan menjelaskan isi kitab adab.

Dalam pelaksanaan pengajian di masjid pondok pesantren Abu hurairah ustadz membahas kitab ma'alim manhaj ahlis sunnah wal jama'ah metode penyampaianya mengunakan kitp yang dibaca dan diartikan serta menjelaaskanya kepada jaam, sedangkan jamaah yang hadir sekitar 55 orang dengan menggunakan protokol covid-19 yang telah ditetapkan seperti menggunakan masker, mengatur jarak selain itu ada doprais yang diberikan setelah selesai pengajian yang bisa menjawab pertanyaan dari ustadz maka akan mendapatkan doprais berupa jubah dan masker ${ }^{24}$

Proses pengajian berlangsung tenang dan aman serta menggunakan media LCD, pengaturan jarak jamaah karena covid-19.

Dari beberapa teori tentang metode dakwah maka metode dakwah Ustadzustadzsalafiyahdalam menginternalisasikan nilai-

22 Hasil Observasi di Masjid Pondok Pesantren Abu Hurairah Mataram pada kamis, 16 juli 2020.Waktu pengajian bakda magrib dan Isya.

23 Wawncara dengan Ustadz Mufi thalib, Lc. (ustadz pondok pesantren Abu hurairah mataram),, wawancara pada jum'at, 17 juli 2020 bakda isya.

${ }^{24}$ Hasil Observasi di Masjid Pondok Pesantren Abu Hurairah Mataram pada jum'at, 17 juli 2020.Waktu pengajian bakda magrib dan Isya. 
nilai kesislaman maka bisa dilihat dari hasil wawancara dengan responden diatas maka bisa disimpulkan Adapun cara menyampaikan pesan dakwah salah satunya bisa dengan metode pengajian dan dalam penyampaian pesan dakwah juga terdapat beberapa cara diantaranya adalah : Dakwah secara tatap muka, digunakan apabila mengharapkan efek perubahan tingkah laku dari masyarakat, pada saat menyampaikan langsung menerima umpan balik, dapat melihat secara langsung dan bisa melihat apabila masyarakat meperhatikan atau menerima dakwah yang disampaikan, hal tersebut dilakukan oleh Ustadzustadz Salafiyah Abu hurairoh mataram ketika berdakwah di lading-lading Lombok utara sebelum covid-19 dan dilanjutkan di masjid Abu hurairah mataram setelah adanya Covid-19

Dakwah melalui media, pada umumnya banyak digunakan untuk dakwah yang bersifat informative seperti hasil wawancara diatas dengan mudir atau pimpinan $\mathrm{Abu}$ hurairah mataram ketika berdakwah menggunkan media Youtube dan TV dakwah seperti Yufid.TV dan Rinjani TV.

Dari materi kajian yang disampaikan dapat disimpulkan bahwa nilai-nilai keislaman yang disampaikan adalah nilai ilahiyah berupa tauhid aqidah dan nilai insaniyah berupa akhlaq hal tersebut dibuktikan dengan materi kajian dengan jadwal terlampir yang memuat materi Aqidah oleh Ustadz Mashudri dan Ustadz Jamaludin materi Akhlaq dan Adab ustadz Mufti Thalib.

Hal tersebut diperkuat dengan kerangka teoritik tentang nilai-nilai kesilaman ilahiyah dan insaniyah. Nilai-nilai keislaman tersebut menurut hasil penelitian Dedi Nur Hasan ${ }^{25}$ yang menyimpulkan bahwa nilai-nilai Al-Islam adalah nilai Ilahiyah dan Insaniyah, nilai Ilahiyah ini mencakup Akidah yaitu nilai iman, islam, takwa, ihsan, syukur, tawakal, dan sabar. Sedang nilai Insaniyah mencakup Akhlaq yaitu nilai Silaturahim, yaitu pertalian rasa cinta kasih pada sesama manusia, Al-Ukhuwah, yaitu semangat persaudaraan,Husnu Al-dzan, yaitu berbaik sangka, Al-Munfiqun, yaitu sikap kaum beriman yang memiliki kesediaan yang besar untuk menolong sesama manusia, Al-Tawadlu, yaitu sikap rendah hati. sebagai berikut:

Nilai Illahiyah berupa materi kajian Aqidah setiap malam jumat oleh Ustadz Jamaludin dengan kajian kitab Aqidah dan Manhaj sedangakan Ustadz Masyhuri menyampaikan kajian Akidaq pada malam senin dengan kitab Qowaidul arba'. Kajian Akidah mencakup tentang Iman, yaitu percaya dan

\footnotetext{
${ }^{25}$ Dhedy Nur Hasan. Nilai Karakter Religius (Agama) dalam Religious Culture. (Malang: UIN Malang.2013). 21
}

yakin dalam hati kemudian diucapkan dengan lisan dan dibenarkan dengan anggotan badan, iman banyak dibicarakan dalam ilmu tauhid. Akidah tauhid merupakan bagian yang paling mendasar dalam ajaran Islam, Tauhid itu sendiri adalah mensatu-kan Allah dalam dzat, sifat, af'al dan beribadah hanya kepada-Nya. Pendapat yang paling kuat dari para Ulama' Ahlussunnah bahwa Tauhid cukup tiga saja yaitu Tauhid Rububiyah, Tauhid Uluhiyah dan Tauhid Asma' wa sifat.

Sedangkan Islam, yaitu Ist-Islam (sikap berserah diri) yang membawa kedamaian kesejahteraan (as salaam) dan dilandasi jiwa yang ikhlas (sincerity). ${ }^{26}$ Menurut Sayyid, Islam adalah kepatuhan kepada hukum-hukum syariat secara keseluruhan yang telah dibawa oleh junjungan kita Nabi Muhammad shallallahu 'alaihi wa sallam. ${ }^{27}$ Nilai-nilai ilahiyah tersebut di internalisasikan melalui pembelajaran Akidah dan melalui ceramah-ceramah Al-Islam seperti pada khotbah jumat, kegiatan IMTAQ dan kultum siraman rohani, dan dalam pendekatan untuk memahaminya hendaknya menggunakan pendekatan normatif dan non normatif. ${ }^{28}$

Nilai Insaniyah berupa materi Akhlaq dan Adab disampaikan oleh Ustadz Mufi Thalib kitab Adab di masjid pondok pesantren Abu hurairoh mataram. Dalam proses dakwah perlu internalisasi nilai Insaniyah yang juga ditanamkan pada jiwa jamaah untuk mendampingi nilai Illahiyah. Nilai Insaniyah yang di internalisasi mencakup nilai Silaturahim yang bisa dilakukan melalui sholat berjamaah di masjid sebagai silaturrahim harian, sholat jumat sebagai silaturrahim mingguan antar warga masyarakat, silaturrahim merupakan pertalian rasa cinta kasih pada sesama manusia, kemudian nilai-nilai insaniyah tercermin dalam pembelajaran Akhlaq sepertiAl-Ukhuwah, yaitu semangat persaudaraan,Husnu Al-dzan, yaitu berbaik sangka, Al-Munfiqun, yaitu sikap kaum beriman yang memiliki kesediaan yang besar untuk menolong sesama manusia (seperti penyaluran daging hewan kurban ke tempat terpencil), AlTawadlu, yaitu sikap rendah hati. Nilai-Nilai Insaniyah mencakup hal-hal sebagai berikut:

Silaturahim, yaitu pertalian rasa cinta kasih pada sesama manusia, khususnya kepada saudara, kerabat, handai taulan, tetangga dan seterusnya. Sifat Al-Husna Allah antara lain adalah kasih (Rahman, Rahim) sebagai satu-satunya sifat Ilahi yang diwajibkan sendiri atas dirinya (QS. Al-An'am:

\footnotetext{
${ }^{26}$ Toto Tasmara, Etos Kerja Pribadi Muslim(Yogyakarta: PT Dana Bhakti Wakaf, 1995), 152.

${ }^{27}$ Sayyid Muhammad bin Salim bin Hafidz, Fiqih \& tasawuf wanita Muslimah, (Surabaya: Cahaya Ilmu, 2008), 25.

${ }^{28}$ Prof. Dr. H. Yunahar Ilyas, Lc. M.A. Kuliah akidah Islam (Yogyakarta: LPPI, 2011) 07.
} 
12) maka manusiapun harus cinta kasih pada sesama, agar Allah cinta kepadanya "irhammu man fi al-ardl, yarhammukum man fi al-sama" kasihilah makhluk yang dibumi maka (dia) yang ada dilangit akan mengasihimu.

Al-Ukhuwah, yaitu semangat persaudaraan, lebihlebih pada sesama seiman (ukhuwah Islamiyah) seperti yang disebutkan dalam Al-Qur'an surat AlHujarat ayat 10-12, yang intinya ialah agar kita tidak mudah merendahkan golongan lain, janganjangan mereka lebih baik dari kita sendiri, tidak saling menghina, saling mengejek, berprasangka buruk, suka mencari-cari kesalahan orang, dan suka mengumpat.

Al-Musawah, yaitu pandangan bahwa semua manusia sama, tanpa memandang jenis kelamin, kesukuan, Bangsa, dan lain-lain. Karena dalam harkat dan hakikatnya adalah sama, tinggi dan rendahnya derajat manusia hanya Allah yang tahu kadar keimanan dan ketakwaanya (QS.AlHujarat: 13).

Al-'Adalah, yaitu wawasan yang seimbang atau balance dalam memandang, menilai, menyikapi sesuatu atau orang dan seterusnya, jadi tidak secara apriori menunjukan sikap positif atau negatif, sikap ini juga disebut tengah (wasth) dan Al-Qur'an menyebutkan bahwa kaum beriman dirancang oleh Allah untuk menjadi golongan tengah (Umat Wasathan) agar dapat menjadi saksi untuk semua umat manusia, sebagaimana kekuatan penengah (QS. Al-Baqarah: 143).

Husnu Al-dzan, yitu berbaik sangka kepada sesama manusia, berdasarkan ajaran Agama manusia pada hakikatnya aslinya adalah baik, karena diciptakan Allah dan dilahirkan atas fitrah kejadian asalnya yang suci, sehingga manusiapun pada hakikatnya adalah makhluk yang berkecendrungan pada kebenaran dan kebaikan.

Al-Tawadlu, yaitu sikap rendah hati, sebuah sikap yang tumbuh oleh keinsyafan bahwa segala kemuliaan hanya milik Allah, maka tidak sepantasnya manusia mengklaim kemuliaan itu kecuali dengan pikiran dan perbuatan yang baik. Itupun hanya Allah yang menilainya (QS. Al-Fathir: 10). Lagi pula kita harus rendah hati karena ingatlah, disetiap orang yang berilmuadalah dia yang maha berilmu.

Al-Munfiqun, yaitu sikap kaum beriman yang memiliki kesediaan yang besar untuk menolong sesama manusia, terutama mereka yang kurang beruntung (fakir miskin yang terbelenggu oleh perbudakan dan kesulitan hidup lainya "raqabah") dengan mendermakan sebagian harta benda yang dikaruniakan dan diamanatkan Tuhan kepada kita. Sebab manusia tidak akan memperoleh kebaikan sebelum mendermakan sebagian harta benda yang dicintainya itu (QS. Ali Imron : 17 dan 93).

\section{Respon Masyarakat Desa Persiapan Rempek Darussalam Terhadap Dakwah Salafi Pasca Gempa}

Respon Jamaah terkait dakwah Asatdizah Salafiyah Pondok Pesantren Abu Hurairoh matarm bisa dilihat dari hasil wawancara dengan beberapa responden di lapangan di bawah ini.

Pertanyaan : bagaimana tanggapan anda tentang dakwah salafi ?

Jawaban: dakwah salaf adalah dakwah yang sesui dengan sunnah rasul artinya dakwah yang benerbenar murni yang menjunjung tinggi tauhid kemudian mengenai dakwah salaf itu sendiri banyak yang menyinggung maupun tidak suka karena ajaran dakwah salf itu sendiri mengembalikan manusia kepada tauhid yak ni mentauhidkan Allah maupun sunnah- sunnah rasul dan menjelaskan apa yang dimaksud dengan bid'ah. setelah peneliti melakukan wawancara dengan jamaah pengajian maka dapat di ambil kesimpulan bahwa jamaah sangat memahami tentang dakwah salafi dan paham betul mengenai ajaran salafi meskipun banyak orang yg menyinggung tentang ajaran salafi tapi jamaah sabar menangapi komentar yag dia dengar. jamaah sering menghadiri kajian salafi dikala ada waktu, pengajian biasanya di adakan di masjid seperti di masjid pondok pesantren abu hurairah mataram. ${ }^{29} 1$ Selain tanggapan diatas terdapat juga tanggapan dan respon dari jamaah yang lain sebagaimana wawancara berikut ini :

Pertanyaan : apa yang anda dapat dalam mengikuti pengajian?

Jawaban: secara pengalaman sebelum saya mengenal dakwah salaf saya juga mendengar dikampung saya juga dakwah salaf ini di benci setelah saya mengenal dakwah ini Alhamdulillah saya belajar di pondok abuhurrairah dan yang saya liat gak ada salahnya sebenernya salafi ini bukan sebuah kelompok atau generasi atau apa dakwah salaf yakni mengikuti dakwah rasul ya ahli sunnah waljama'ah jika memang dakwah salaf ini di benci sampai saat ini juga belum ada yang bisa memberikan alas an dimana letak dakwah salaf ini itu aja. setelah peneliti melakukan wawancara dengan jamaah pengajian maka dapat di ambil kesimpulan bahwa jamaah sangat menyukai dakwah salafi ini karna dakwah salafi ini mengerjakan ajaran yang sesui tuntunan sunnah rasulullah iya juga menjunjung tinggi sunnah rasulullah mencoba mengenalkan dakwah salafi

${ }^{29}$ Wawancara dengan Ahmad Yani : Jamaah kajian salafiyah di Pondok Pesantren Abu hurairoh mataram, Rabu 7 Juli 2020 Pukul 20:00. 
kedalam masyarakat bahwa dakwah salafi ini tidak seburuk pandangan masyarakat yang belum mengenal jelas dakwah salafi tersebut, jamaah juga menempuh pendidikanya dari SDIT, SMPIT, SMAIT di pondok pesantren abuhurairah Mataram. ${ }^{30}$

Dalam pelaksanaan pengajian di masjid pondok pesantren Abu hurairah ustadz membahas kitab ma'alim manhaj ahlis sunnah wal jama'ah metode penyampaianya mengunakan kitab yang dibaca dan diartikan serta menjelaaskanya kepada jaam, sedangkan jamaah yang hadir sekitar 50 orang dengan menggunakan protokol covid-19 yang telah ditetapkan seperti menggunakan masker, mengatur jarak selain itu ada doprais yang diberikan setelah selesai pengajian yang bisa menjawab pertanyaan dari ustadz maka akan mendapatkan doprais berupa jubah dan masker. ${ }^{31}$

Proses pengajian berlangsung tenang dan aman serta menggunakan media LCD, pengaturan jarak jamaah karena covid-19.

Respon yang lain juga dari salah seorang jamaah kajian salafiyah yang bernama Asrul Muhammad sebagai berikut:

Pertanyaan: bagaimana tangapan anda tentang dakwah salafi?

Jawaban: dakwah salafi adalah dakwah yang mengajak masyarakat dakwah yang mengajak umat islam kembali kedalam agamanya yang murni agama yang dimaksud sunnah rasulullah salallahualaihi wassalam yang diajarkan kepada para sahabat tampa adanya penambahan, pengurangan ataupun perubahan benar benar menjaga kemurnian islam yang di bawa oleh rasulullah salallahualaihi dan ini perintah Allah dalam al- qur'an Allah berfirman yang artinya dan apapun yang rasul itu ajarkan hendaklah kalian kerjakan dan apapun yang dia larang hendaklah iya tinggalkan dalam ayat yang lain yang artinya sapa yang taat kepada rasul maka sungguh iya taat kepada Allah dalam hadis rasullah juga mewasiatkan kepada kita yakni umat muslim untuk kembali kepada sunnah rasulullah salallahualaihi wassalam dan berpegang teguh di atas ajaranya nabi bersabda yang artinya hendaklah kalian berpegang teguh dengan sunnah $k u$ dan sunnah para khulafa arrasidin dan dakwah salafi juga mengajak masyarakat mengajak umat islam agar memahami alquran dan hadis sesui dengan pemahamanya para sahabat nabi kenapa karna inilah satu atunya pemahaman yang benar dalam agama Allah berfirman yang artinya dan orang yang masuk islam pertama kali dalam kalangan

\footnotetext{
${ }^{30}$ Wawancara dengan Davit : Jamaah kajian salafiyah di Pondok Pesantren Abu hurairoh mataram, Kamis 8 Juli 2020 Pukul 20:00.

31 Hasil Observasi di Masjid Pondok Pesantren Abu Hurairah Mataram pada senin, 08 juli 2020.Waktu pengajian bakda magrib dan Isya.
}

muhajirin dan anshor dan orang orang yang mengikuti mereka maka Allah akan ridhokepada mereka dan mereka ridho kepada Allah dan Allah menyiapkan bagi mereka surge surge yang mengalir dibawahnya sungai sungai seperti itu jadi Allah yang telah memberikan rekomendasi yaitu Allah ridhokepda para sahabat dan ridho orang orang yang mengikuti jejak kakinya para sahabat nabi salallahualaihi wasallam ${ }^{32}$.

Setelah peneliti melakukan pertanyaan dengan jamaah dapat di simpulan bawa jamaah sangat menjuung tinggi ajaran salaf ini maksudnya ahli sunnah waljamaah diamana ajaran ini mempelajari Al-Qur'an dan hadis rasulullah salallahualaihi wassalam.

Dalam pelaksanaan pengajian di masjid pondok pesantren Abu hurairah ustadz membahas kitab ma'alim manhaj ahlis sunnah wal jama'ah metode penyampaianya mengunakan kitab yang dibaca dan diartikan serta menjelaaskanya kepada jaam, sedangkan jamaah yang hadir sekitar 50 orang dengan menggunakan protokol covid-19 yang telah ditetapkan seperti menggunakan masker, mengatur jarak selain itu ada doprais yang diberikan setelah selesai pengajian yang bisa menjawab pertanyaan dari ustadz maka akan mendapatkan doprais berupa jubah dan masker ${ }^{33}$

Proses pengajian berlangsung tenang dan aman serta menggunakan media LCD, pengaturan jarak jamaah karena covid-19.

Jamaah saat diwawancarai mengatakan mengenai bahwa dia sangat bersyukur dengan adanya kajian rutin ustadz- ustadz salafiyah dia memberikan apresiasi kepada para ustadz yang dengan suka rela memberikan motivasi dan bimbingan agama yang disampaikan lewat ceramah mereka yang menambah pengetahuan agama dan memberikan semangat dalam beribadah. ${ }^{34}$

Jamaah yang lain menjelaskan bahwa terkait dengan kajian atau dakwahnya dia menilainya sangat bagus, itu terlihat dari materi dakwah yang disampaikan. ${ }^{35}$

Ahmad yani memberikan tanggapan positif terkait dakwah Asatdizah Salafiyah, dia merasakan manfaat yang luar biasa dengan kajian Salafi dan juga ceramah yang disampaikan pun sangat bagus, dimana kajiannya menambah ilmu tentang ibadah

\footnotetext{
${ }^{32}$ Hasil wawancara dengan Asrun muhammad, di Masjid pondok pesantren Abu hurairah mataram wawancara pada senin, 09 juli 2020 bakda isya

${ }^{33}$ Hasil Observasi di Masjid Pondok Pesantren Abu Hurairah Mataram pada senin, 09 juli 2020.Waktu pengajian bakda magrib dan Isya.

${ }^{34}$ Davit, jamaah kajian rutin asatdizah salafiyah di masjid Abu huraroh mataram, wawancara rabu 7 juli 2020 pukul 20:00

${ }^{35}$ Abu Ibrohim: Jamaah Kajian asatidzah salafiyah di masjid pondok pesantren Abu Hurairah Mataram dan masjid Lawata Mataram.
} 
yang benar beliau menegaskan dakwah salafiyah adalah dakwah yang sesuai dengan sunnah Rosul. ${ }^{36}$

Asrul Muhammad memberikan tanggapan terkait dengan dakwah ustadz- ustadz salafiyah Salafi adalah dakwah yang mengajak umat islam untuk kembali ke agamanya yang murni sesuai dengan tuntunan Rosulullah shollallahu 'alaihi wa sallam ${ }^{37}$.

Maka bisa disimpulkan bahwa respon jamaah terhadap dakwah ustadz- ustadz salafiyah dalam menginternalisasikan nilai-nilai kesilaman di pondok pesantren Abu hurairah mataram lebih dominan kepada respon positif dan jika dikaitkan dengan teori respon maka mendekati dengan teori respon yang bersifat Afektif, dimana terlihat adanya semangat dan antusias jamaah ketika menyambut kajian dengan materi yang sudah terjadwal lengkap dengan pemateri dan kita yang dikaji.

Berdasarkan teori yang dikemukakan oleh Steven M. Chaffe tentang respon yang dibagi menjadi 3 yaitu :

a. Kognitif, yaitu respon yang berkaitan erat dengan pengetahuan keterampilan dan informasi seseorang mengenai sesuatu. Respon ini timbul apabila adanya perubahan terhadap yang dipahami oleh khalayak.

b. Afektif, yaitu respon yang berhubungan dengan emosi, sikap dan menilai seseorang terhadap sesuatu.

c. Behavioral, yaitu respon yang berhubungan dengan perilaku nyata meliputi tindakan atau kebiasaan. ${ }^{38}$

\section{SIMPULAN DAN SARAN}

Dari pembahasan diatas mengacu pada bagaimana metode dakwah ustadz- ustadz salafiyah Pondok Pesantren Abu Hurairah dalam menginternalisasikan nilai-nilai keislaman melalui pengajian rutin di lading-lading Lombok Utara dan di masjid Abu Hurairah Mataram, maka dapat disimpulkan sebagai berikut;

a. Metode dakwah Ustadz- ustadz Salafiyah memiliki dua garis besar yaitu metode dakwah secara umum dalam bentuk pola seperti mengadakan halaqoh majelis ilmu, dauroh, mendirikan yayasan, mendirikan media siaran dakwah dan secara khusus dalam bentuk pelaksanaan pengajian rutin dengan pemateri dan materi yang sudah terjadwal rapi.

pukul 21:00

${ }^{36}$ Edi Susanto, masyarakat Dusun Busur, wawancara 1 Agustus,

${ }^{37}$ Asrul Muhammad, jamaah kajian rutin asatdizah salafiyah di masjid Abu huraroh mataram, wawancara rabu 19 juli 2020 pukul 20:00

${ }^{38}$ Jalaluddin Rakhmat, Psikologi Komunikasi, Bandung: Remaja Rosdakarya, 2004, hal. 64 b. Terkait dengan respon jamaah terhadap dakwah Ustadz- ustadz salafiyah pondok pesantren Abu hurairoh mataram beberapa tanggapan msyarakat yang merasakan dampak positif dengan adanya kajian rutin tersebut denga respon afektif dalam teori respon.

c. Penelitian sebelum covid-19 dilakukan di lading-lading Lombok Utara sekitar 2 pekan yang selanjutnya peneliti ditarik dari lokasi penelitian dengan alas an covid-19 dan pengajian rutin ustadz- ustadz salafiyah Pondok pesantren Abu hurairoh juga dipindahkan ke masjid Pondok Pesantren Abu hurairoh mataram sehingga lokasi penelitian lebih banyak di masjid pondok pesantren Abu hurairah mataram setela covid-19.

\section{SARAN}

1. Bagi para ustadz- ustadz salafiyahagar senantiasa meningkatkan ikhlas dalam berdakwah dan terus memperbaiki metodek dakwahnya sehingga bisa diterima dengan baik di tengah masyarakat dengan mengedepankan dakwah tauhid dakwah sunnah yang ikhlas dan tetap mengikuti manhaj Rosulullah shollallahu 'alaihi wa sallam demi kemaslahatan Umat.

2. Kepada para simpatisan dakwah salafiyah dan kepada Masyarakat agar melihat secara objektif dengan cara menghadiri kajian-kajian keislaman dakwah salafiyah baru memberikan respon secara obyektip dan tidak terfitnah dengan fitnah-fitnah tanpa bukti yang ilmiyah tentang dakwah salafiyah.

\section{DAFTAR RUJUKAN}

Al-Qur'an dan terjemah, edisi Tahun 2002,Departemen Agama RI,

Abdullah Salim Bahammam, 2016, panduan fiqh ibadah bergambar, cet II, Zam-Zam, Solo.

Arifin Anwar, 2011, Dakwah Kontemporer (sebuah studi kasuskomunikasi), Graha Ilmu, Yogyakarta.

Alwisral dan H. Khaidar, 2005, Strategi Dakwah Dalam Membentuk Da'i Dan Khatib Profesional, Radar Jaya Offset, Jakarta.

Abu Zu'rar, Seputar Gerakan Islam, 2009, Al-Azhar Press, Bogor.

Abdullah bin Muhammad, 2008, Tafsir Ibnu Katsir (jilid 4), Pustaka Imam Syafi'i, Jakarta.

Abdul 'Azhim bin Badawi Al-Khalafi, 2007, Al-wajiz , Pustaka As-Sunnah, Jakarta.

Basit Abdul, 2017, Dakwah Antar Individu teori dan aplikasi, CV. Tretrem Nusa, Porwokerto. 
Cholid Narbuko dan H. Abu Achmadi, 2016, Metode Penelitian, PT.Bumi Aksara, Jakarta.

Dedy Mulyana, 2008, Ilmu Komunikasi suata pengantar, PT Remaja Rosdakarya, Bandung.

Daryanto, 2016, Mulyo Rahardjo, teori komunikasi, Gava medika, Yogyakarta.

https://pakarkomunikasi.com/pengertiankomunikasi-menurut-para-ahli

Iwan Supriadin, Dakwah Kultural perspektif dialog antarbudaya, 2015, Madani Publishing Mataram, Mataram.

M Zaki Abdillah, Al-I'lam; Jurnal Komunikasi dan Penyiaran Islam, Vol. 1, No 2, March 2018, pp

H.Munzier dan H.Harjani, 2015, Metode Dakwah, cet 4, Prenadamedia Group, Jakarta.

M. Djunaidi Ghony dan Fauzan Almanshur, 2016, Metodologi Penelitian Kualitatif, Ar-Ruzz Media, Jogjakarta.

Maulana Muhammad Sa'ad al-Kandahlawi, 2007, Munthakab Ahadits, As-Shaff, Yogyakarta.

Maulana Muhammad Zakariyya, 2007, Himpunan Fadhilah Amal, As-Shaff, Yogyakarta.

Nana Rukmana, 2015 Masjid dan Dakwah merencanakan, membangun dan mengelola masjid, Al-Mawardi Prima,

Sugiyono, 2015, Metode Penelitian Kuantitaif, Kualitatif, Dan R\&D, Alfabeta, Bandung.

Sindung Haryanto, 2016, Sosiologi Agama Dari Klasik Hingga Postmodern, Ar-Ruzz Media, Yogyakarta. 